\title{
Performance determinants of large-small business strategic alliances in South Africa
}

\author{
F. Ahwireng-Obeng* \\ Graduate School of Business Management, \\ University of the Witwatersrand, PO Box 98, Wits 2050, Republic of South Africa \\ Ahwireng-Obeng.F@wbs.wits.ac.za \\ O.O. Egunjobi \\ Formerly MBA student, Graduate School of Business Administration, \\ University of the Witwatersrand \\ Received 1 April 2001
}

\begin{abstract}
The literature suggests that the success of strategic alliances between large and small firms is influenced by four broad factors: motivational, cultural and resource capability synergies; shared commitments, goals and roles; participative planning, operationalisation and administration; and regular open communications. This study suggests that even though mismatches and incongruencies may be evident, the alliance formation and endurance are influenced by two other factors: largely similar perceptions by both groups regarding the alliance's performance determinants; and a strong expectation by the large firm group of high future net benefits from aligning with small firms. Performance is, invariably, contingent upon implementing a number of 'pre-emptive' steps during the course of the alliance.
\end{abstract}

*To whom all correspondence should be addressed.

\section{Introduction}

Contrary to predominant international experience, large (white) firms in South Africa have been driven into strategic alliances with small (black) firms neither voluntarily nor by purely economic considerations. Rather, they have been overwhelmingly spurred by the desire to conform with the government's aggressive policy of empowering small firms as a demonstration of good corporate citizenship. Such a politically motivated act is not entirely inconsistent with 'good business' as long as it is intended to maximize the present value of the expected net benefits arising from subsequent transactions (Black, 1993). These observations emerge from the present study aimed at identifying what managers of the two groups consider to be the major underlying causes of failure or success of strategic alliances between their firms. In essence, the study suggests that these performance determinants are pertinent to South Africa's changeable business setting, and outlines strategic and preventive steps that could be adopted in similarly fluid and unsettled conditions elsewhere.

Managing strategic alliances involves procedures including, strategy development, partner selection, planning, formalizing, operationalizing and administering the relationship. Ultimately, the management challenge demands amongst other things, aligning partner compatibilities and resolving conflicts. These tasks are difficult to perform in a working environment that is changeful and speculative. Many South African firms are, however, progressively realizing that with increased competition, demand, uncertainty, and rapid and numerous technological advances, their long-term survival depends on building partnerships in similar businesses. In fact, the intensity of rivalry and market globalisation, increasing complexity of the management role and the possibility of mutual gains from linkaging are among the major considerations for alliance formation in that country (Abela, 1995). The objectives are to obtain new capability, defend a position, gain access to markets, reduce risks and improve returns, and to benefit from the sharing of resources (ibid:130). Therefore, by seeking to establish the major impacting factors on alliance performance, this study attempts to amplify insight of the South African experience.

Recent progress in small business development in South Africa is associated with an on-going wave of down - or right-sizing among large businesses. There are three reasons for this tendency. First, 'principal-agent' problems identified with the structure of modern large enterprises, that is, the separation of ownership (by shareholders) from control (by managers) confers informational advantage on the latter which enables them to pursue their own objectives not necessarily compatible with those of the owners. This contradiction can be resolved, at least partly, through downsizing by outsourcing non-core activities or subcontracting selected essential functions to reduce monitoring costs and save overhead and other input expenditures. Second, new technologies have markedly reduced the expense of obtaining inputs from outside 
suppliers. Additionally, South African small businesses enjoy structurally-induced cost and employment generation advantages over large enterprises (South African Foundation,1998).

The Government White Paper (1995) ${ }^{1)}$ on the promotion of small business defines a small business as an established business employing between 5 and 49 workers assumed to be formally registered, clearly demarcated and paying taxes on a regular basis. A medium sized enterprise employs between 50 and 199 workers. Tables 1 and 2 show the contribution by micro, small, medium and large enterprises to Gross Domestic Product (GDP) and employment respectively.

South Africa's tertiary or services sector contributes 69,9 percent to GDP of which the largest contributors are the business and other services industry including the public sector $(19,0 \%$ and $19,5 \%$ respectively) and to a lesser extent trade and transport $(13,9 \%$ and $11 \%$ respectively). Manufacturing is the single largest sector contributing 19,8 percent to GDP. The contribution of the primary sector, agriculture and mining, is very small - a combined contribution to GDP of 10,3 percent. The total real GDP for 2000 is estimated to be about R565,000 million.

Table 1(b) provides a breakdown of size-class of each sector's contribution to GDP. 28,95 percent of the GDP is generated by small and medium enterprises, and 65,2 percent by large enterprises. Sectors in which small and medium enterprises contribute more than 40 percent to the GDP are agriculture, construction, trade and transport.

The contribution by size-class to employment in the respective industrial sectors is shown in Table 2. Large enterprises contribute 45,2 of all formal employment compared to 54,5 by the smaller classifications. Most of the employment in these classes occur in agriculture, construction, trade, transport and the services sectors.

The attractiveness of small firms is also evident in Table 3 where the first column shows them to be much less import intensive than large firms, and in column two wage costs per job to be lower for small firms than for large ones. In the last three columns are data on value added per unit of gross output. They show higher value addition for small firms despite their higher wage component (higher labour intensity).

\footnotetext{
${ }^{1)}$ The Government White Paper distinguishes between 'survivalist' and microenterprises operating within the informal sector. Survivalist enterprises generally consist of one-person operators using little or no capital and generating a turnover well below the poverty datum line. Micro-enterprises employ between one and four workers and have a turnover averaging less than the VAT (value added tax) registration limit of R150 000 per annum $(\$ 1=$ R6.7 in April 2000).
}

Table 1a: Sectoral contribution to GDP: 2000

\begin{tabular}{c|c}
\hline Sector & \% Contribution \\
\hline Agriculture & 4,4 \\
Mining & 5,9 \\
Manufacturing & 19,8 \\
Electricity & 3,6 \\
Construction & 2,8 \\
Trade & 13,9 \\
Transport & 11,0 \\
Business Services & 19,0 \\
Other Services & 19,6 \\
\hline
\end{tabular}

Source: South African Reserve Bank, Quarterly Bulletin December 2000.

Table 1b: Percentage contribution by size-class to the GDP in the industrial sectors

\begin{tabular}{l|l|l|l|l|l}
\hline & Micro & Small & \multicolumn{1}{|c}{ Medium } & Large & Total \\
\hline Agriculture & 4,13 & 8,67 & 43,71 & 43,49 & 100,00 \\
\hline Mining & 1,01 & 1,74 & 2,55 & 94,70 & 100,00 \\
\hline Manufacturing & 5,27 & 7,37 & 21,02 & 66,34 & 100,00 \\
\hline Electricity & 0,00 & 0,00 & 0,00 & 100,00 & 100,00 \\
\hline Construction & 3,14 & 35,60 & 12,20 & 49,06 & 100,00 \\
\hline Trade & 2,27 & 23,41 & 17,12 & 57,21 & 100,00 \\
\hline Transport & 7,07 & 18,50 & 20,30 & 54,13 & 100,00 \\
\hline $\begin{array}{l}\text { Business \& } \\
\text { Other services }\end{array}$ & 14,90 & 12,90 & 2,90 & 69,30 & 100,00 \\
\hline $\begin{array}{l}\text { Average : } \\
\text { All sectors }\end{array}$ & 5,82 & 13,90 & 15,05 & 65,23 & 100,00 \\
\hline
\end{tabular}

Source: Ntsika Annual Review, 2000.

Table 2: Percentage contribution by size-class employment in the main industrial sectors

\begin{tabular}{l|l|l|l|l|l}
\hline & Micro & \multicolumn{1}{|c|}{ Small } & \multicolumn{1}{|c}{ Medium } & Large & Total \\
\hline Agriculture & 4,17 & 13,81 & 52,31 & 29,71 & 100,00 \\
\hline Mining & 0,92 & 2,51 & 2,59 & 93,97 & 100,00 \\
\hline Manufacturing & 8.39 & 10,57 & 24,58 & 56,46 & 100,00 \\
\hline Electricity & 0,00 & 0,00 & 0,00 & 100,00 & 100,00 \\
\hline Construction & 2,93 & 37,28 & 13,45 & 16,34 & 100,00 \\
\hline Trade & 35,77 & 23,73 & 13,00 & 27,49 & 100,00 \\
\hline Transport & 11,38 & 23,50 & 20,81 & 41,27 & 100,00 \\
\hline $\begin{array}{l}\text { Business } \\
\text { services }\end{array}$ & 25,14 & 19,18 & 5,20 & 50,18 & 100,00 \\
\hline Other services & 52,68 & 19,22 & 823 & 20,86 & 100,00 \\
\hline $\begin{array}{l}\text { Average: } \\
\text { All sectors }\end{array}$ & 17,38 & 16,34 & 20,76 & 45,52 & 100,00 \\
\hline
\end{tabular}

Source: Ntsika Annual Review, 2000.

Table 3: Selected coefficients

\begin{tabular}{l|l|l|l|l|l}
\cline { 4 - 6 } & \multicolumn{2}{c}{} & \multicolumn{3}{c}{$\begin{array}{c}\text { Value added per unit } \\
\text { of gross output }\end{array}$} \\
\cline { 2 - 6 } & $\begin{array}{c}\text { Imports } \\
\text { per unit of } \\
\text { gross } \\
\text { output }\end{array}$ & $\begin{array}{c}\text { Wage Costs } \\
\text { per job } \\
\text { (R) }\end{array}$ & Wages & $\begin{array}{c}\text { Gross } \\
\text { operating } \\
\text { surplus }\end{array}$ & Total \\
\hline Small Firms & 0,06 & 31875,83 & 0,23 & 0,24 & 0,47 \\
\hline Large Firms & 0,10 & 33182,64 & 0,22 & 0,19 & 0,41 \\
\hline Total & 0,09 & 32760,21 & 0,22 & 0,20 & 0,43 \\
\hline Small/Large & 0,57 & 0,96 & 1,01 & 1,31 & 1,15 \\
\hline
\end{tabular}

Source: South Africa Foundation, 1998. 


\section{The importance of this research}

South Africa's history of having previously segregated and disadvantaged black people, also synonymous with small businesses and the survivalist micro-enterprise sector, gives an ample reason to assume that a fundamental tension - a cultural incompatibility - exists between black and white business managers. Such cultural asymmetry or lack of perceptual, behavioural and management capability synergies is considered in the literature to be unconducive to alliance formation and success. On the other hand, the prevailing climate of uncertainty that characterizes countries in transition encourages alliance formation for survival. This curious contradiction is the rationale for the empirical investigation which attempted to elicit perceptual responses of the managers on the performance determinants of strategic alliances between their firms in the postindependence (1994) South African business experience. The objectives were two-fold. First, to establish the extent of congruence of their alliance experience with international practice. And consequently, to develop a framework for implementing such alliances in changing working environments. The following two testable propositions were derived from the literature on the basis of their recurrent frequencies:

(1) The major causes of failure of strategic alliances between large and small firms are: (i) overly optimistic expectations; (ii) lack of planning; (iii) lack of trust; (iv) poor communication; and (v) lack of shared goals.

(2) The key factors contributing to the success of strategic alliances between large and small firms are: (i) selecting the right partner; (ii) support and commitment of top management; (iii) clearly understood roles; (iv) regular communication between partners; (v) and clearly defined objectives .

Sections two and three respectively review the literature and describe the research methodology adopted. Section four analyses and interprets the results with section five concluding and drawing implications from the study.

\section{The nature of strategic alliances}

\section{Definition}

According to Williamson (1991:271) the term 'strategic alliance' (SA) refers to a range of inter-organisational relationships 'in which the parties ( .....) maintain autonomy but are bilaterally dependent to a non-trivial degree'. Thus, the term came to mean almost anything in firm-level transactional relationship without regard to its essence as a strategic option for participating firms. Consequently, Maynard (1996) suggests that a true SA is one in which the companies have examined their core competencies and future paths and have found a source of synergy and areas of complementary strengths including the sharing of risks and exploitation of opportunities. In this regard, SA is a cooperative effort by two or more entities in pursuit of their own strategic objectives. It involves commitment and sharing of resources including money, technology and people and is defined by business relationships among autonomous partners.

\section{Perspectives}

Much of the writing on strategic alliances originate from three perspectives - economics, corporate strategy and organizational studies. From the economics viewpoint SA is a hybrid of resource allocation modes ranging from hierarchy to markets, research usually centred on international business and transaction cost analysis. (Williamson, 1991; Gomes-Casseres, 1996). Research work in corporate strategy has progressed steadily from the role of senior management in controlling alliances in the 1980s and early 1990s (Hamel, Doz \& Prahalad, 1988; Ohmae, 1989) through emphasis on the role of the business unit in alliance, (KPMG, 1997) to the management of alliances at the firm level, particularly with regard to the growing alliance failures. To date, there appears to be no consensus on this issue (Osborn \& Hagedoorn, 1997). The organizational approach has, so far, emphasized two areas: the institutionalization of the alliance process, especially the patterns of survival, growth and sustainability, and the technology and learning aspects of alliance experience (ibid).

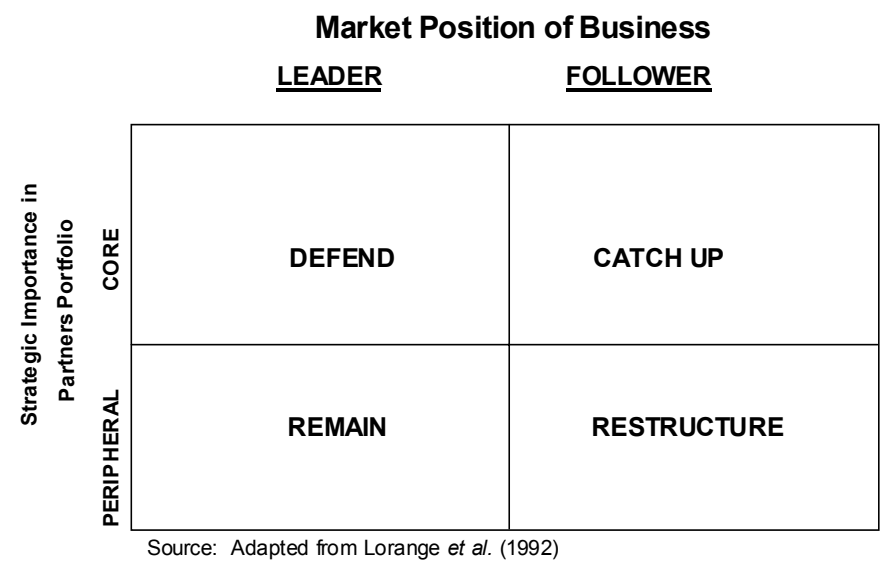

Motives

The prime motives for seeking strategic alliances can be captured by a simple matrix of four factors in Figure 1 . First, the strategic importance of the business segment within which the alliance is being contemplated and how it fits the overall portfolio of the partner, the alternatives being whether it is of core or peripheral importance. Second, the firm's relative position in the business segment under consideration that being either of a leader or a follower. Based on these considerations four generic motives can be classified as those enabling the firm to: defend; catch up; remain in business; or restructure (Lorange \& Roos, 1992). When a business is of importance to a firm which is also a leader in the particular activity, the firm would want access to new competencies, markets, technologies or other resources to sustain its competitive advantage over time. However, where the business is core to the portfolio of a 
firm which is a follower in the specific business segment, strategic alliances are used to strengthen the competitive position towards becoming a leader. By the same logic, when a firm is a leader in a segment that is peripheral to its operations and its main focus is to remain in that business, alliance is a means of achieving that objective more efficiently. Finally, the motive to restructure occurs when a firm is a follower in a particular business which plays a peripheral role in its portfolio.

\section{Benefits}

Historically, alliances have provided a means for firms to survive in highly uncertain environments, improve their ability to exploit complex business opportunities, spread risks, innovate and grow without increasing its payroll. (Cawson, 1994). More specifically, alliances: improve purchasing and foster supplier-customer relations; empower companies with similar assets to benefit from the economies of scale of their allied assets; augment synergies to the benefits among firms with similar visions and complementary competencies; widen markets and enhance visibility; and improve technology transfer (Maynard, 1996).

\section{Influencing factors}

In regard to these benefits, the more neighbouring factors influencing alliance formation are: industry characteristics and structure, the domestic macro-environment of business, and the magnitude and probability of risks. For example, alliances are frequent in the textile and clothing industry as well as the engineering services industry, and both industries are characterized by a high level of risk and a 'multiplicity of trade' (Bidaults, Lurent \& Segal, 1992).

With respect to the influence of domestic business environmental factors, the convergence of consumer needs and preferences resulting from globalisation is a strong catalyst. A dragging factor, however, is the high perceived risks when there are well-publicised cases of firms having suffered from alliance failures. Quite often, these failures arise from misappropriation of technology transfers, the loss of control over operations, the possibility that a partner may become a stronger competitor, and the loss of competitive advantage, that is, core competencies through 'decentralisation' (Gugler, 1992).

\section{Strategic alliances between large and small firms}

Small firms frequently face the challenge of survival and developing a sustainable strategy for growth. Bodkin and Matthews (1992) have employed the value chain concept, or the process by which a new idea gets to the market to illustrate this situation. They group the various stages of the value chain into three phases as: Phase 1 (research, development and design); phase 2 (manufacturing and fabrication); and phase 3 (marketing sales and distribution). They then argue that small firms hardly get beyond the first phase due to a lack of access to raw-materials and components, finance, technology, product markets and government support. Strategic alliances with large firms allow the small firm to gain access to these resources while maintaining their independence and work culture (Slowiniski, Seeling \& Hull, 1996). The large firm, on the other hand, benefits from the speed, innovation and flexibility of the small firm.

According to the literature, alliances between firms of similar size are difficult and complex; they are much more delicate and complicated than between large and small firms (Maynard, 1996). Among the key reasons for frequent large-small firm alliance failures are: lack of alliance experience; lack of proper planning and management; lack of commitment; lack of shared goals, benefits and risks; lack of trust; poor communication; overly optimistic expectation; mismatch of skills and resources and consequent power imbalance (Maynard, 1996; Vyas, Shelburn \& Rogers, 1995; Slowinski, 1996; Marks \& Marvis, 1998; Ellram, 1992)

On the other hand, key success factors include: good strategic match between partners; documentation of agreements to ensure commitment from partners; clear understanding of goals and roles; direct communication and multiple relationship building between partners; frequent performance feedback; shared risks and resources; integration of information systems; alignment of culture; building a scope for flexibility, and learning into the alliance agreement. Finally, internal and external stakeholder support plays an important role.

\section{Methodological procedures}

The target population primarily comprised managers of small firms in strategic alliance with large firms, as well as those of large firms in alliance with small firms. Managers of firms facilitating such alliances were also researched. An example of the third firm category is Ebony Consulting International which facilitates an United States funded programme.

As the study was aimed at a restricted population, non probability sampling was used combining convenience and snowballing procedures ${ }^{2)}$. For the same reason, a $100 \%$ sample of 160 firms was marked. Initial respondents were identified through Small and Medium Enterprise (SME) support organizations and the alliance promoting institutions.

A combination of the survey method of questionnaire administration by means of facsimile, electronic mail and personal direct in-depth interviews was used to collect data. Most of the respondents were previously contacted by telephone to enhance a high response rate which, indeed, was 75 percent or 120 completed and returned questionnaires. Additionally, 104 of the respondents

\footnotetext{
${ }^{2)}$ Convenience sampling refers to the procedure of obtaining sampling units which are the most conveniently available. This sampling method is often used to obtain responses quickly and economically (Zimund, 1997). Snowball sampling is a technique in which additional respondents are obtained from information provided by the initial respondents. It is used to locate members of rare populations by referrals (ibid).
} 
permitted personal direct interviews. The investigation took place in Johannesburg between March and June 1999.

The questionnaire schedule consisted of three sections. The first sought data on previous alliance experience, its type and duration. The second section contained a list of 14 items extracted from the literature as causes of alliance failure. A similar list of 17 success determinants constituted the third section. Respondents were then required to rate, on a five-point Likert scale, the extent of their concurrence with a statement embodying each performance determinant.

The purpose of the personal interviews was to seek qualitative data and insight on the remaining issues of the survey which were: motivation for alliance formation; steps taken in the alliance formation process; differences between large-small-firm alliances and those involving firms of similar size; major considerations in partner selection; implementation of monitoring and performance feed-back; and channels of communication utilized.

Correspondence analysis is a multivariate technique that allows for the geometric representation of a contingency table in two dimensional space (Bendixen \& Sandler, 1995). The technique was used to convert the ordinal scale data from the questionnaire schedule to interval scale data. This allowed for ranking of the items in decreasing order of their mean scores, and the use of such statistical test as the two sample t-test to evaluate similarity or difference between the perceptions of respondents. The Spearman Rank Correlation test was used to determine statistical association between the rankings of the two groups.

\section{Analysis and interpretation}

\section{Alliance experience, type and duration}

Table 4 presents characteristics of the firms surveyed by prior alliance experience, the alliance type and duration. Less than 50 percent of the sample including all large firms and only ten small firms have had some experience of strategic alliance in the past. Most small firms had experienced exclusive or simple alliances whereas all large firms had engaged in only multiple or network alliances. For most large firms the duration was over 10 years; for almost all small firms, however, alliance experience was less than five years, that is, they were formed for the first time after the fall of apartheid in 1994. Almost all the large white firms had formed their pre-1994 alliances with other white firms of varying sizes.

Table 4: Alliance experience, type and duration

\begin{tabular}{c|c|c|c|c|c|c|c|c|c}
\hline $\begin{array}{c}\text { Firm } \\
\text { size }\end{array}$ & \multicolumn{2}{|c|}{$\begin{array}{c}\text { Prior alliance } \\
\text { experience }\end{array}$} & \multicolumn{4}{c|}{ Type of alliance } & \multicolumn{3}{c}{ Duration of alliance } \\
\hline & Yes & No & Total & Network & Exclusive & Total & < 5 yrs & 5-10yrs & $>$ 10yrs \\
\hline Small & 10 & 62 & 72 & 2 & 8 & 10 & 8 & 2 & 0 \\
\hline Large & 48 & 0 & 48 & 48 & 0 & 48 & 9 & 7 & 32 \\
\hline & 58 & 62 & 120 & 50 & 8 & 58 & 17 & 9 & 32 \\
\hline
\end{tabular}

\section{Determinants of alliance failures}

The mean scores by all firms for each of the 14 items are presented in Table 5. The five highest ranked are: lack of continuous monitoring; poor communications between parties; lack of shared goals; lack of top management support; and lack of shared risks and benefits.

\section{Table 5: Factors responsible for failure - mean scores}

\begin{tabular}{c|l|c|c}
\hline Determinant & \multicolumn{1}{|c|}{ Statement } & Mean & Rank \\
\hline 14 & Lack of continuous monitoring of the alliance & 4,66 & 1 \\
\hline 7 & Poor communications between partners & 4,54 & 2 \\
\hline 5 & Lack of shared goals & 4,53 & 3 \\
\hline 8 & Lack of top management support & 4,48 & 4 \\
\hline 6 & Lack of shared risks and benefits & 4,47 & 5 \\
\hline 13 & Overly optimistic expectations & 4,46 & 6 \\
\hline 9 & Inadequate up-front planning & 4,43 & 7 \\
\hline 10 & Lack of trust & 4,34 & 8 \\
\hline 3 & $\begin{array}{l}\text { Lack of commitment of resources to the } \\
\text { alliance }\end{array}$ & 4,32 & 9 \\
\hline 4 & Slow results & 4,30 & 10 \\
\hline 2 & Cultural differences between partners & 4,29 & 11 \\
\hline 12 & Power imbalance between partners & 4,17 & 12 \\
\hline 11 & $\begin{array}{l}\text { Mismatch or unequal levels of skills and } \\
\text { resources }\end{array}$ & 4,11 & 13 \\
\hline 1 & Lack of prior experience with alliances & 4,09 & 14 \\
\hline
\end{tabular}

These include only two of the five propositions drawn from the literature - 'poor communications' and 'lack of shared goals'. This might suggest that the propositions are unsupported. It is, however, worth noting that the difference between the highest mean score $(4,66)$ and the lowest mean score $(4,09)$ is not substantial $(0,57)$. All 14 factors may therefore be regarded as sufficiently important to be considered as real causes of failure in accordance with the literature.

\section{Table 6: Factors responsible for failure - small firms}

\begin{tabular}{c|l|c|c}
\hline Determinant & \multicolumn{1}{|c|}{ Statement } & Mean & Rank \\
\hline 14 & Lack of continuous monitoring of the alliance & 4,64 & 1 \\
\hline 4 & Slow results & 4,55 & 2 \\
\hline 5 & Lack of shared goals & 4,51 & 3 \\
\hline 7 & Poor communications between partners & 4,51 & 4 \\
\hline 9 & Inadequate up-front planning & 4,50 & 5 \\
\hline 13 & Overly optimistic expectations & 4,45 & 6 \\
\hline 8 & Lack of top management support & 4,43 & 7 \\
\hline 11 & Lack of shared risks and benefits & 4,42 & 8 \\
\hline 12 & Mismatch or unequal levels of skills and & 4,33 & 9 \\
\hline 10 & Posources & 4,16 & 10 \\
\hline 2 & Lack of trust & 4,15 & 11 \\
\hline 3 & $\begin{array}{l}\text { Lack of commitment of resources to the } \\
\text { alliance }\end{array}$ & 4,01 & 13 \\
\hline 1 & Lack of prior experience with alliance & 3,93 & 14 \\
\hline
\end{tabular}


Table 7: Factors responsible for failure - large firms

\begin{tabular}{c|l|c|c}
\hline Determinant & \multicolumn{1}{|c|}{ Statement } & Mean & Rank \\
\hline 3 & $\begin{array}{l}\text { Lack of commitment of resources to the } \\
\text { alliance }\end{array}$ & 4.66 & 1 \\
\hline 2 & Cultural differences between partners & 4.65 & 2 \\
\hline 14 & Lack of continuous monitoring of the alliance & 4.65 & 3 \\
\hline 7 & Poor communications between partners & 4.63 & 4 \\
\hline 5 & Lack of shared goals & 4.60 & 5 \\
\hline 10 & Lack of trust & 4.48 & 6 \\
\hline 6 & Lack of shared risks and benefits & 4.47 & 7 \\
\hline 8 & Lack of top management support & 4.41 & 8 \\
\hline 13 & Overly optimistic expectations & 4.36 & 9 \\
\hline 9 & Inadequate up-front planning & 4.33 & 10 \\
\hline 12 & Power imbalance between partners & 4.14 & 11 \\
\hline 1 & Lack of prior experience with alliances & 4.10 & 12 \\
\hline 4 & Slow results & 4.01 & 13 \\
\hline 11 & $\begin{array}{l}\text { Mismatch or unequal levels of skills and } \\
\text { resources }\end{array}$ & 3.68 & 14 \\
\hline
\end{tabular}

Comparing the five top-ranked items for the two groups (Tables 6 and 7) reveals three common determinants: 'lack of continuous monitoring'; 'lack of shared goals'; and 'lack of communications between partners'. The Spearman Rank Correlation test (Table 11) for all 14 factors, however, found no statistically significant similarity in them, neither did the two-sample t-test analysis (Table 12) show statistically significant difference between their perceptions. Only two factors: 'slow results' $(\mathrm{t}=2,598)$ and 'mismatch or unequal level of skills and resources' $(t=2,124)$ were significantly different in the ratings of the two groups. Table 12 further shows that the small firm group considered these two influences more important (mean scores 4,55 and 4,33) than did the large firm group (mean scores 4,01 and 3,68).

The in-depth interviews provide the reasons for this observation by identifying the three key motivations for large-small firm strategic alliances in South Africa to be: the government's black empowerment and affirmative action drive that coerced many large firms to get into partnerships with small black firms as a means of gaining access to government contracts; the belief that linking up with black business was an expression of social responsibility with long term expected benefits; and the realization that such partnerships would, in any case, make business sense both by focusing on core business to reduce cost and opening access to previously unexploited markets. Thus, black small-firm managers expected not only to exploit alliances for rapidly building their management resource capacities, but also to generate huge, financial returns. The failure to realize these expectations in the projected time frames represents only part of a range of mismatches between the two groups. Indeed, the two significantly different variables are synchronous. Together they reflect the disappointment of black managers over continued material power imbalance since their alliances were formed. In addition, the second variable partly symbolizes such mismatches as the lack of motivational synergies described earlier, attitudinal and cultural differences and a lingering lack of reciprocal trust and commitment. The penultimates refer to paternalistic disposition of white firm managers, and the frequent complaint from their black counterparts of 'not being comfortable with them'.

\section{Determinants of alliance successes}

The highest ranked movers of success are: regular communication between partners; selecting the right partner; a clearly defined plan for the alliance; clearly defined and shared objectives; and frequent performance feedback (Table 8). Only two of these form part of the five-part proposition on success determinants. They are: 'communication between partners' and 'partner selection'. Like the previous results on failure determinants, this result may appear to falsify the research propositions. Yet, all the mean scores are reasonably high with only minor variations as they range narrowly from 4,80 to 3,96 . In this sense, all 17 items may be considered relevant determinants of success. Our finding is, therefore, consistent with the literature. Interestingly, 'lack of prior experience' was ranked last among the prime causes of failure and 'prior experience' also ranked last among success determinants. This confirms previous alliance experience as the least important of influences on performance considered in this study.

\section{Table 8: Key success factors - mean scores}

\begin{tabular}{c|l|c|c}
\hline Determinant & \multicolumn{1}{|c|}{ Statement } & Mean & Rank \\
\hline 4 & Communication between partners & 4,80 & 1 \\
\hline 1 & Selecting the right partner & 4,763 & 2 \\
\hline 7 & A clearly defined plan for the alliance & 4,762 & 3 \\
\hline 5 & Clearly defined and shared objectives & 4,757 & 4 \\
\hline 9 & Frequent performance feedback & 4,742 & 5 \\
\hline 2 & Top management commitment & 4,738 & 6 \\
\hline 3 & Clear understanding of roles & 4,71 & 7 \\
\hline 10 & $\begin{array}{l}\text { Continuous measuring, monitoring and } \\
\text { reviewing }\end{array}$ & 4,68 & 8 \\
\hline 17 & A clearly defined payback timeline & 4,55 & 9 \\
\hline 11 & Shared risks and resources & 4,51 & 10 \\
\hline 8 & $\begin{array}{l}\text { Close ties between senior management of } \\
\text { partners }\end{array}$ & 4,49 & 11 \\
\hline 16 & Support of internal and external stakeholders & 4,48 & 12 \\
\hline 6 & Strong personal relationships between partners & 4,44 & 13 \\
\hline 12 & $\begin{array}{l}\text { Partners must share basic values and a } \\
\text { common }\end{array}$ & & \\
\hline 13 & culture & 4,38 & 14 \\
\hline 14 & A flexible alliance agreement & 4,21 & 15 \\
\hline 13 & Integration of Information Systems & 4,16 & 16 \\
\hline & Prior experience with alliances & 3,96 & 17 \\
\hline & & & \\
\hline
\end{tabular}

The separate rankings by large and small firms are shown in Tables 9 and 10. The result of the Spearman Rank Correlation test on the five highest ranked success factors 
among the two groups is also presented in Table 11 and suggests a significant similarity. That there was no overall significant difference is confirmed by the two-sample t-tests at both 90 and 95 percent confident levels (Table 13). At 90 percent confident level, however, there was a significant difference in the mean scores for two items: 'partners must share basic values and a common culture' $(t=3,014)$ and 'a clearly defined payback timeline' $(\mathrm{t}=1,792)$. The large firms considered the former more important (mean score 4,741) than did small firms (mean score 4,172). On the other hand, the small firms considered the latter more important (mean score 4,754) than did the large firms (mean score 4,206).

These observations corroborate our interpretation of the two sources of alliance failure found to be statistically different in the ratings of the two groups. Indeed, 'mismatches or unequal level of skills and resources' and 'partners must share basic values and a common culture' together reflect the fact that the two groups share neither skills and resources equally nor basic values and a common culture. Similarly, 'slow results' and 'a clearly defined payback timeline' mirror the small-firm group's high expectation of and frustration with the benefits reaped, so far, from the government's affirmative action policy.

\section{Table 9: Key success factors - small firms}

\begin{tabular}{|c|c|c|c|}
\hline Determinant & Statement & Mean & Rank \\
\hline 9 & Frequent performance feedback & 4,79 & 1 \\
\hline 7 & A clearly defined plan for the alliance & 4,78 & 2 \\
\hline 17 & A clearly defined payback timeline & 4,75 & 3 \\
\hline 1 & Selecting the right partner & 4,73 & 4 \\
\hline 2 & Top management commitment & 4,73 & 5 \\
\hline 5 & Clearly defined and shared objectives & 4,72 & 6 \\
\hline 4 & Communication between partners & 4,71 & 7 \\
\hline 3 & Clear understanding of roles & 4,68 & 8 \\
\hline 10 & $\begin{array}{l}\text { Continuous measuring, monitoring and } \\
\text { reviewing }\end{array}$ & 4,66 & 9 \\
\hline 16 & Support of internal and external stakeholders & 4,58 & 10 \\
\hline 6 & Strong personal relationships between partners & 4,56 & 11 \\
\hline 8 & $\begin{array}{l}\text { Close ties between senior management of } \\
\text { partners }\end{array}$ & 4,56 & 12 \\
\hline 11 & Shared risks and resources & 4,55 & 13 \\
\hline 14 & Integration of Information Systems & 4,38 & 14 \\
\hline 15 & A flexible alliance agreement & 4,19 & 15 \\
\hline 12 & $\begin{array}{l}\text { Partners must share basic values and a } \\
\text { common culture }\end{array}$ & 4,17 & 16 \\
\hline 13 & Prior experience with alliance & 3,97 & 17 \\
\hline
\end{tabular}

Table 10: Key success factors - large firms

\begin{tabular}{c|l|c|c}
\hline Determinant & \multicolumn{1}{|c|}{ Statement } & Mean & Rank \\
\hline 4 & Communication between partners & 4,90 & 1 \\
\hline 1 & Selecting the right partner & 4,77 & 2 \\
\hline 5 & Clearly defined and shared objectives & 4,77 & 3 \\
\hline 2 & Top management commitment & 4,74 & 4 \\
\hline 12 & $\begin{array}{l}\text { Partners must share basic values and a } \\
\text { common culture }\end{array}$ & 4,74 & 5 \\
\hline 3 & Clear understanding of roles & 4,73 & 6 \\
\hline 7 & A clearly defined plan for the alliance & 4,71 & 7 \\
\hline 9 & Frequent performance feedback & 4,67 & 8 \\
\hline 10 & $\begin{array}{l}\text { Continuous measuring, monitoring and } \\
\text { reviewing }\end{array}$ & 4,67 & 9 \\
\hline 11 & Shared risks and resources & 4,49 & 10 \\
\hline 8 & $\begin{array}{l}\text { Close ties between senior management of } \\
\text { partners }\end{array}$ & 4,41 & 11 \\
\hline 16 & Support of internal and external stakeholders & 4,29 & 12 \\
\hline 15 & A flexible alliance agreement & 4,24 & 13 \\
\hline 17 & A clearly defined payback timeline & 4,21 & 14 \\
\hline 6 & Strong personal relationships between partners & 4,19 & 15 \\
\hline 13 & Prior experience with alliance & 3,94 & 16 \\
\hline 14 & Integration of Information Systems & 3,87 & 17 \\
\hline & & & \\
\hline
\end{tabular}

Table 11: Spearman rank correlation test

\begin{tabular}{c|c|c|c|c}
\hline Determinant & $\begin{array}{c}\text { Spearman's } \\
\text { Rank } \\
\text { Correlation } \\
\text { Coefficient }\end{array}$ & $\begin{array}{c}\text { Calculated } \\
\text { T statistic }\end{array}$ & $\begin{array}{c}\text { Critical t } \\
\text { value } \\
\mathbf{9 0 \%} \\
\text { Confidence } \\
\text { Level }\end{array}$ & $\begin{array}{c}\text { Critical t } \\
\text { value } \\
\mathbf{9 5 \%} \\
\text { Confidence } \\
\text { Level }\end{array}$ \\
\hline Failure & $-0,02$ & 0,0685 & 1,782 & 2,179 \\
\hline Success & 0,493 & 2,1925 & 1,753 & 2,131 \\
\hline
\end{tabular}

Table 12: t-test results - failure determants

\begin{tabular}{c|c|c|c}
\hline \multicolumn{5}{c}{ Mean Score } \\
\hline Determinant & Small & Large & T-value \\
\hline 1 & 3,931 & 4,095 & 0,344 \\
\hline 2 & 4,128 & 4,653 & 1,554 \\
\hline 3 & 4,009 & 4,663 & 1,598 \\
\hline 4 & 4,549 & 4,006 & 2,598 \\
\hline 5 & 4,509 & 4,600 & 0,422 \\
\hline 6 & 4,421 & 4,472 & 0,242 \\
\hline 7 & 4,509 & 4,633 & 0,568 \\
\hline 8 & 4,431 & 4,409 & 0,105 \\
\hline 9 & 4,495 & 4,331 & 0,802 \\
\hline 10 & 4,150 & 4,479 & 0,934 \\
\hline 11 & 4,333 & 3,675 & 2,124 \\
\hline 12 & 4,161 & 4,144 & 0,052 \\
\hline 13 & 4,452 & 4,364 & 0,414 \\
\hline 14 & 4,637 & 4,645 & 0,050 \\
\hline
\end{tabular}


Table 13: t-test results - success determinants

\begin{tabular}{|c|c|c|c|}
\hline \multicolumn{4}{|c|}{ Mean Score } \\
\hline Determinants & Small & Large & T-value \\
\hline 1 & 4,734 & 4,774 & 0,299 \\
\hline 2 & 4,732 & 4,741 & 0,079 \\
\hline 3 & 4,68 & 4,728 & 0,278 \\
\hline 4 & 4,711 & 4,902 & 1,695 \\
\hline 5 & 4,723 & 4,774 & 0,357 \\
\hline 6 & 4,559 & 4,186 & 1,196 \\
\hline 7 & 4,777 & 4,708 & 0,597 \\
\hline 8 & 4,558 & 4,412 & 0,787 \\
\hline 9 & 4,791 & 4,665 & 0,714 \\
\hline 10 & 4,659 & 4,665 & 0,032 \\
\hline 11 & 4,549 & 4,492 & 0,276 \\
\hline 12 & 4,172 & 4,741 & 3,014 \\
\hline 13 & 3,965 & 3,944 & 0,066 \\
\hline 14 & 4,384 & 3,875 & 1,680 \\
\hline 15 & 4,189 & 4,238 & 0,119 \\
\hline 16 & 4,580 & 4,288 & 1,437 \\
\hline 17 & 4.754 & 4.206 & 1.792 \\
\hline
\end{tabular}

\section{Conclusion, implications and recommendations}

\section{Conclusion}

This paper has investigated the perceptions of large (white) and small (black) firm managers in South Africa regarding the major determinants of success and failure of strategic alliances between the two groups. Nearly all the failure determinants scored highly, the first five being: the lack of continuous monitoring; poor communication between partners; and the lack of shared goals, top management support, and shared risks and benefits. The corresponding success factors are : constant and effective communications between partners; right partner selection; clearly defined objectives as well as plans; and frequent performance feedback.

There was no statistically significant difference in overall group perceptions on determinants of failure except two factors - 'slow results' and 'mismatch or unequal levels of skills and resources', both of which the smaller firms rated more important than did the large firms. Neither was there any significant similarity between the groups in their rankings. However, they were concurrent on three of the five most important factors - 'lack of continuous monitoring'; 'poor communications'; and 'lack of shared goals'. All 14 factors were considered important to varying degrees.

With regard to success factors, there was no overall statistically significant difference in group perception. On the other hand, the rankings showed a significant similarity. This suggests that both large and small firms had broadly similar perceptions of the relative importance of success factors. None of the five propositions appeared statistically confirmed by our findings. However, all factors considered were found to be of importance rendering our results consistent with the literature.

\section{Implications}

It can be implied from this study, that the Affirmative Action (or Black Economic Empowerment) policy of the South African government to enhance and develop small firms has succeeded in compelling large firms to form alliances with the former despite divergent resource endowments, values, cultures and expectations. Whether the policy is perceived by large firm managers as undesirably coercive or exacting a shrewd act of social responsibility with long-term economic benefits, it was at the onset a potential contributor to alliance failure. Contrarily, the positive impact of such policies, confirmed in this study, seldom features in the international literature.

The results of the quantitative analysis together with insight acquired from the interviews provide a broad framework for implementing successful large-small firm alliances. Five strategic steps constitute this framework: identifying gaps and capabilities in the prospective organization; setting clear alliance objectives; selecting a suitable alliance partner; setting the terms of agreements; and periodic evaluation and monitoring.

\section{Identifying gaps and capabilities}

At this early stage, the firm will have to decide what segment of its business activities requires to be allied. It must also establish and define the rationale for an alliance, analyse the strengths, weaknesses, of prospective partners and attract top management support.

\section{Setting clear alliance objectives}

The objectives could be wide-ranging but should be clear and articulate enough to be understood by both parties as they impact not only on the alliance agreement but also on the choice of alliance model.

\section{Selection of a suitable alliance partner}

This stage links strongly with the previous stages. Both large and small firms must establish synergies in regard to cultural fit, resource capacities, commitments, trust and communication outlets. Synergies are important to ensure value addition to the alliance by both parties as well as mutual gain from it. Cultural fit or being 'comfortable with a partner' in terms of business values and peoples culture are primarily important for building trust and easing communication which in turn breed honesty and openness required for favourable outcomes. Alliances take time to work and for the benefits to realize, hence the need for longterm commitments. There are other group-specific alliance success criteria. Small firms must particularly demonstrate the technical capability to deliver on expectations, and have a track record of sound managerial skills and financial backing. Alternatively, it is incumbent on the larger partner 
to ensure that these criteria are met. In fact, it must empower the small firm not because this is a deed of social responsibility but because it is a genuine means of getting to build the resource-constrained firms' capacity to maximize mutually desirable business results.

\section{Setting the terms of the agreement}

A formal business agreement is always essential and must include measurable goals as well as clearly defined roles and expectations.

\section{(v) Constant evaluation and monitoring}

This stage is probably the most critical. Once communication lines have been identified by parties, regular contacts including formal meetings are essential to provide a forum for structured feedback on continuous basis.

When evaluated against this five-step strategic guideline for successful alliance formation, the South African experience is characteristically haphazard and unsystematic, and falls short of a deliberate grand design. Quite often, the small firm, unlike a large firm, is too small to be departmentalized so that the whole firm rather than a part of it joins the alliance. The implication is that the small firm is more severely affected in the event of alliance failure. Furthermore, since the choice of a partner is overwhelmingly influenced by the political connections of the small firm proprietor in order to win government contracts, such other important considerations as synergy, cultural fit and relevant capabilities are overlooked. Besides, most alliances are formed without formal business agreements that would clarify goals, define roles and expectations and determine lines of communication. Indeed, only in a quarter of the sample population was a facilitating consultant involved in the process of alliance formation, and in almost all cases the project appeared to have performed quite well.

Many of the respondents felt that although they were aware of several of the steps required to ensure successful alliances, these were not followed because of the political nature of the exercise. While this contributed to alliance failure generally, it was widely held that the reluctance of small firms to make honest disclosures about their capabilities coupled with existing inter-group power imbalances have added a great deal. For a typical small firm experiencing cash flow problems, financial support in the form of flexible payment terms and on-time payment was identified as an important success factor. In their own interest small firms must ensure that the lines of communication are not limited to regular meetings but are kept alive at transactional and operational levels. Monitoring, on the other hand, is a mutual responsibility of both partners with the large firm playing a mentoring role. Finally, the role of a neutral consultant should be restricted to the actual putting together of the alliance such as providing technical support in the form of business plans and management infrastructure, and in settling disputes that may arise. The running of the alliance must be left to the partners.

\section{Recommendations for future research}

Strategic alliances between small and large firms is a relatively new phenomenon in the South African business environment. They have been directly driven by government black economic empowerment policy and understandably motivated by such considerations as good social responsibility other than those underlying strategic alliance formation elsewhere. Therefore, an interesting area for future research would be the prime movers and impact of 'genuine' large-small firm strategic alliances devoid of government intervention. Furthermore, this research does not distinguish between alliances in specific industries. Therefore, future industry-specific research should identify the particular forces that must be taken into account in finetuning alliance management strategies.

\section{References}

Abela, M.C. 1995. Objectives behind strategic alliances in South Africa. Unpublished MBA Research Report, Graduate School of Business Administration, University of the Witwatersrand, Johannesburg.

Bendixen, M.T. \& Sandler, M. 1995. 'Converting verbal scales to interval scales using correspondence analysis', Bestuurdinamika, 4(1):31-49.

Bidault C., Laurent, P. \& Segal, C. 1992. 'Competitive and co-operative strategies in engineering services', Long Range Planning, 25(3):43-49.

Bidault, F. \& Cunnings, T. 1994. 'Innovation through alliance: Specimens and limitations. $R \& D$ Management, 24(1):33-45.

Batkin, J. \& Matthews, I. 1992. Winning combinations: The new wave of entrepreneurial partnerships between large and small companies. New York: John Wiley and Sons.

Black, P.A. 1993. 'Affirmative action: Rational response to a changing environment', South African Journal of Economics, 61(4):317-323.

Cawson, A. 1994. 'Innovation and consumer electronics'. In Dodqson, M \& Rothwell, E. (Eds.). The handbook of industrial innovation. Chelton, UK: Elgar.

Ellram, L. 1995. 'Partnering pitfalls and success factors', International Journal of Purchasing and Materials Management, 31(2):36-44.

Garai, G. 1999. 'Leveraging the rewards of strategic alliances', Journal of Business Strategy, 20(2):40-43.

Gomes-Casseres, B. 1994. 'Group versus group: How alliance networks compete', Harvard Business Review, Jul-Aug:62-74.

South Africa. Department of Trade and Industry. 1995. White Paper on National Strategy for the Development and Promotion of Small Business in South Africa. Pretoria: Department of Trade and Industry. 
Gugler, P. 1992. 'Building transnational alliances to create competitive advantages', Long-Range Planning, 25(1):90-99.

Hemel, G., Doz, Y.L. \& Prahalad, C.K. 1989. 'Collaborate with your competitors and win', Harvard Business Review, Jan-Feb:133-135.

Institute of Development Studies. 1997. Collective efficiency: A way forward for small firms. Policy Briefing Issue No 10, University of Sussex, Brighton.

KPMG Transaction Services. 1997. Joint ventures: A triumph of hope our Reality.

Lorrange, P. \& Roos, J. 1992. Strategic alliances. Oxford UK: Oxford/Blackwell.

Maynard, R. 1996. 'Striking the right match', Nations Business, 84(5):18-20.

Minshall, T.H.W. 1999. 'A resourced-based view of alliances: The case of the handheld computer industry', International Journal of Innovation Management , 3(2):159-183

Mitchell, L. \& Mirvis, P. 1998. Joining forces: Making one plus one equal to three in mergers, acquisitions and alliances. San Francisco: Jesey-Bass.

Ntsika. 2000. The state of small business in South Africa. Pretoria: Department of Trade and Industry.

Ohmae, K. 1989. 'The global logic of strategic alliances', Harvard Business Review, 67(2):143-155.

Osborn, R.N. \& Hagedoorn, J. 1997. 'The institutional and evolutionary dynamics of inter-organisational alliances and networks', Academy of Management Journal, April:261-278.

Pekar, P. \& Allio, R. 1994. 'Making alliances work Guidelines for success', Long Range Planning, 26(6): 4153.

Pridis, T. 1992. 'Strategic alliances for smaller firms', Research in Global Strategic Management, 3:129-142.

Rai, A., Borah, S. \& Ramaprassadi, A. 1996. 'Critical success factors for strategic alliance in the information technology industry: An empirical study', Decision Sciences, 27(1):141-155.

Saski, T. 1993. 'What the Japanese have learnt from strategic alliances', Long Range Planning, 26(6):41-53.

South Africa Foundation. 1998. 'Big and small business in South Africa: Where the twine meets', Viewpoint, December.

Segil, L. 1998. 'Strategic alliances for the 21st century', Planning Review, 26(4):12-16.
Slowinski, G., Seeling, G., \& Hull, F. 1996. 'Managing technology-based strategic alliance between large and small firms', Sam Advanced Management Journal, 27(3):42-47.

Stafford, E.R. 1994. 'Using co-operative strategies to make alliances work', Long Range Planning, 27(3):64-74.

Stiles, J. 1994. 'Strategic alliances: Making them work', Long Range Planning, 27(4):133-137.

Tallman, S.B. \& Shenker, O. 1994. 'Internal co-operative venture strategies: Outward investment and small firms from NIC's', Management International Review, Special Issue, 31:60-74.

Williamson, O.E. 1991. 'Comparative economic organisation: The analysis of structural alternatives', Administrative Science Quarterly, 36: 269-296.

Yoshino, M.Y. \& Shnivasa-Rangan, V. 1995. Strategic alliances: An entrepreneurial approach to globalisation. Boston, MA: Harvard Business School Press.

Vyas, N. Shelburn, W. \& Rogers, D. 1995. 'An analysis of strategic alliances: Forms, functions and framework', Journal of Business and Industrial Marketing, 10 (3):4760 .

Zikmundi, W.G. 1997. Business research methods. Orlando: Harcourt Brace. 